\title{
Wear Particles Promote Reactive Oxygen Species-Mediated Inflammation via the Nicotinamide Adenine Dinucleotide Phosphate Oxidase Pathway in Macrophages Surrounding Loosened Implants
}

\author{
Weishen Chen ${ }^{a}$ Ziqing Lia Ying Guo ${ }^{b}$ Yuhuan Zhouc ${ }^{c}$ Ziji Zhanga \\ Yangchun Zhang ${ }^{a}$ Guotian Luo ${ }^{a}$ Xing Yanga Weiming Liao ${ }^{a}$ Chaohong Lic \\ Lingwu Chen $^{d}$ Puyi Sheng ${ }^{a}$

\begin{abstract}
aDepartment of Orthopaedic Surgery, The First Affiliated Hospital of Sun Yat-sen University, ${ }^{b}$ Department of Endocrinology, Sun Yat-sen Memorial Hospital, Sun Yat-sen University, 'Department of Histology and Embryology, Zhongshan School of Medicine, Sun Yat-sen University, dDepartment of Urology, The First Affiliated Hospital of Sun Yat-sen University, Guangzhou, China
\end{abstract}

\section{Key Words}

Prosthesis loosening • Wear particles • ROS • NOX • Apocynin

\begin{abstract}
Background/Aims: Prosthesis loosening is closely associated with chronic inflammatory cytokine secretion by macrophages, which are activated by wear particles or inflammatory stimulants such as lipopolysaccharide (LPS). Reactive oxygen species (ROS) are critical regulators of inflammation, but their enzymatic sources in response to wear particles and their effects on peri-implant LPS-tolerance remain unclear. Methods: Three ROS-related enzymesnicotinamide adenine dinucleotide phosphate oxidase (NOX)-1 and -2 and catalase-were investigated in interface membrane tissues and in titanium (Ti) particle-stimulated macrophages in vitro. The generation of ROS and downstream inflammatory effects were measured with or without pre-incubation with apocynin, an NOX inhibitor. Results: Pre-exposure to Ti particles attenuated NF-KB activation in LPS-stimulated macrophages, indicating that wear particles suppress immune response, which may lead to chronic inflammation. NOX-1 and -2 were highly expressed in aseptically loosened interface membranes and in macrophages stimulated with Ti particles; the particles induced a moderate amount of ROS generation, NF-KB activation, and TNF- $\alpha$ secretion in macrophages, and these effects were suppressed by apocynin. Conclusion: Wear particles induce ROS generation through the NOX signaling pathway, resulting in persistent inflammation and delayed loosening. Thus, the suppression of NOX activity may be a useful strategy for preventing prosthesis loosening.
\end{abstract}

Copyright (C) 2015 S. Karger AG, Basel

Puyi Sheng, MD, PhD, Professor and Lingwu Chen, MD, PhD, Professor

KARGER 125
Department of Orthopaedic Surgery, The First Affiliated Hospital of Sun Yat-sen University and Department of Urology, The First Affiliated Hospital of Sun Yat-sen University, \#58 Zhongshan 2nd Road, Guangzhou 510080 (China)

E-Mail shengpuyi@hotmail.com and E-Mail chenlingwu@hotmail.com 


\section{Cellular Physiology Cell Physiol Biochem 2015;35:1857-1867 \begin{tabular}{l|l} 
and Biochemistry $10.1159 / 000373996$ & $\begin{array}{l}\text { D } 2015 \text { S. Karger AG, Basel } \\
\text { Published online: March 26, 2015 }\end{array}$ \\
\cline { 2 - 3 }
\end{tabular}}

\section{Introduction}

Prosthesis loosening is the most common long-term complication of total joint arthroplasty and is the main reason for revision surgeries [1]. Implant wear particles generated from repetitive movement between components of joint prostheses play a prominent role in chronic aseptic inflammation, periprosthetic osteolysis and progressive prosthesis loosening [2,3]. The inflammation is characterized by the infiltration and activation of macrophages $[4,5]$. Contact with, or phagocytosis of, wear particles induces a series of pathophysiological responses in macrophages, including the activation of nuclear factor (NF)- $\kappa \mathrm{B}$ and the secretion of proinflammatory cytokines such as tumor necrosis factor (TNF)- $\alpha$, and interleukin (IL)-1 $\beta$, IL-6, and IL-8 $[2,4,6,7]$, resulting in a decrease in osteoblast function and increase in osteoclast activity. This promotes the resorption and suppresses the formation of bone, eventually leading to periprosthetic osteolysis and loosening [4, 8-10].

Reactive oxygen species (ROS) are critical regulators of inflammation. ROS production has been observed in various cell types exposed to wear particles [4,11-13], which induces NF- $\kappa B$ activation and local inflammation $[14,15]$. The intracellular ROS level is regulated by oxidative enzymes including nicotinamide adenine dinucleotide phosphate (NADPH) oxidase (NOX) and anti-oxidative enzymes such as catalase (CAT), glutathione peroxidase, and superoxide dismutase [16-18]. Upon stimulation with bacteria or bacterial components such as lipopolysaccharide (LPS), the induction and activation of NOX and the downregulation and suppression of CAT synergistically contribute to the generation of large amounts of ROS, thus mediating powerful microbicidal activity and a strong inflammatory reaction $[15,16,18,19]$. Among members of the NOX family, NOX-2 (also known as gp91phox) is basically expressed in by phagocytes (i.e., macrophages and neutrophils) and is activated by exposure to microorganisms or inflammatory factors [16]. Besides, the induction of NOX-1 in macrophages by LPS is also evidenced [18]. Taken together, the LPS-triggered upregulation of NOX and downregulation of CAT contribute to the accumulation of ROS in macrophages and to local inflammation. However, little is known about the manner in which wear particles affect these enzymes in macrophages and their role in LPS tolerance in peri-implant tissues.

The present study investigated the involvement of NF- $\mathrm{KB}$ in wear particle-induced LPS tolerance in macrophages to determine the role of ROS - which can potently activate NF$\kappa \mathrm{B}$-in particle-induced inflammation. The expression of three ROS-related enzymes (NOX-1 and -2 and CAT) in interface membranes surrounding implants with aseptic loosening was examined. Moreover, ROS and their related enzymes, as well as NF- $\kappa$ B activation and TNF- $\alpha$ secretion, were evaluated in macrophages in response to titanium (Ti) particles or LPS in vitro in order to elucidate the mechanism of peri-implant oxidative stress and subsequent inflammatory responses. We also tested whether the NOX inhibitor apocynin [20] has a protective effect against peri-implant inflammation.

\section{Materials and Methods}

\section{Patients and samples}

Samples of synovial membrane-like interface tissue between bone and implant $(n=10)$ were obtained upon revision total hip arthroplasty (THA) that was performed due to aseptic loosening (7 men, 3 women; mean age, 60.5 years) (Table 1). Eight total hips were originally performed due to femur head necrosis (FHN) and two were due to femur neck fracture (FNF). The mean time from primary THA to revision THA was 11 years. Diagnosis of aseptic loosening was confirmed based on clinical and radiological evaluation. Subjects indicated negative results for bacterial and fungal cultures. As control samples, synovial membranes ( $\mathrm{n}=8)$ were collected from cases undergoing primary THA for FHN ( 6 cases) or FNF ( 2 cases) ( 6 men, 2 women; mean age 56.8 years). Patients with inflammatory arthritis or other local or systemic immune diseases were excluded. Clinical samples were fixed immediately in 10\% neutral formalin for $24-48 \mathrm{~h}$, followed by dehydration in ethanol, clearing in xylene, and embedding in paraffin.

\section{KARGER}




\section{Cellular Physiology Cell Physiol Biochem 2015;35:1857-1867 \begin{tabular}{ll|l} 
and Biochemistry & $\begin{array}{l}\text { DOI: 10.1159/000373996 } \\
\text { Published online: March 26, 2015 }\end{array}$ & $\begin{array}{l}\text { ○ 2015 S. Karger AG, Basel } \\
\text { www.karger.com/cpb }\end{array}$ \\
\hline
\end{tabular} Chen et al.: Wear Particles Promote Inflammation Through NOX}

Table 1. Preoperative data for aseptic loosening patients. FNF, femur neck fracture; FHN, femur head necrosis; THA, total hip arthroplasty; UHMWPE, ultrahigh molecular weight polyethylene; A, both components; B, acetabular cup; C, prosthesis stem

\begin{tabular}{ccccccccc}
\hline Case no. & $\begin{array}{c}\text { Age } \\
\text { (years) }\end{array}$ & Sex & $\begin{array}{c}\text { Reason for } \\
\text { arthroplasty }\end{array}$ & $\begin{array}{c}\text { Years from primary } \\
\text { THA to revision }\end{array}$ & Type of alloy & $\begin{array}{c}\text { Type of } \\
\text { liner }\end{array}$ & $\begin{array}{c}\text { Type of } \\
\text { fixation }\end{array}$ & $\begin{array}{c}\text { Loosened } \\
\text { parts }\end{array}$ \\
\hline 1 & 70 & F & FNF & 3 & CoCrMo & UHMWPE & Cemented & A \\
2 & 65 & M & FHN & 8 & TiAlV & UHMWPE & Cementless & B \\
3 & 76 & F & FNF & 10 & TiAlV & UHMWPE & Cemented & A \\
4 & 56 & M & FHN & 8 & CoCrMo & UHMWPE & Cementless & A \\
5 & 48 & M & FHN & 18 & TiAlV & UHMWPE & Cementless & A \\
6 & 78 & F & FHN & 13 & CoCrMo & UHMWPE & Cemented & A \\
7 & 63 & M & FHN & 11 & CoCrMo & UHMWPE & Cementless & A \\
8 & 40 & M & FHN & 16 & TiAlV & UHMWPE & Cemented & A \\
9 & 56 & M & FHN & 15 & CoCrMo & UHMWPE & Hybrid & A \\
10 & 53 & M & FHN & 8 & TiAIV & UHMWPE & Cementless & C \\
average & 60.5 & & & 11 & & & & \\
\hline
\end{tabular}

Patients and samples were selected from all patients in the Joint Department of the First Affiliated Hospital of Sun Yat-sen University between March 2009 and January 2010. The patients were fully aware of the project and provided written, informed consent for their participation. The study protocol was approved by the ethical committee of the First Affiliated Hospital of Sun Yat-sen University.

\section{Immunofluorescence analysis}

The protocol for immunofluorescence staining was performed as described in our previous research [21]. Paraffin sections were cut at a thickness of $4 \mu \mathrm{m}$, deparaffinized in xylene, and rehydrated sequentially in 100\%, 90\%, 70\%, and 50\% ethanol. Antigen retrieval was performed by pressure cooking in Tris-EDTA buffer for $3 \mathrm{~min}$. Sections were treated with 3\% normal goat or rabbit serum for $1 \mathrm{~h}$ and incubated with rabbit anti-human NOX-1, goat anti-human NOX-2 (Santa Cruz Biotechnology, Inc., Santa Cruz, CA, USA), or rabbit anti-human CAT (Epitomics, Burlingame, CA, USA) antibodies (all used at $1: 200$ ) at $4{ }^{\circ} \mathrm{C}$ in humidified chambers. After three washes in phosphate-buffered saline (PBS), the sections were incubated for $2 \mathrm{~h}$ at room temperature with Dylight 488-conjugated goat anti-rabbit IgG or Dylight 594-conjugated rabbit antigoat IgG (both at 1:400, from Earthox, San Francisco, CA, USA). All sections were counterstained with DAPI $(2 \mu \mathrm{g} / \mathrm{mL})$ and examined using a fluorescence microscope (Zeiss, Oberkochen, Germany).

Three visual fields at high magnification were randomly chosen from each section. The expression of NOX-1 and -2 and CAT was quantitatively analyzed using Image Pro Plus 6.0 software (Media Cybernetics Inc., Rockville, MD, USA). Immunoreactivity was assigned an optical density (OD) value: OD = integrated OD/total selected area.

\section{Preparation of Ti particles}

Pure Ti particles were purchased from Alfa Aesar (\#00681; Ward Hill, MA, USA). The mean diameter of the particles was $3.23 \pm 2.66 \mu \mathrm{m}$, as determined by scanning electron microscopy and Image Pro Plus 6.0 software (Media Cybernetics Inc.) (Fig. 1a, b). Particles were baked at $180^{\circ} \mathrm{C}$ for $6 \mathrm{~h}$ for sterilization, followed by treatment with $70 \%$ ethanol for $48 \mathrm{~h}$ to remove endotoxins, as previously described $[22,23]$. Prior to use, the particles were confirmed to contain less than $0.1 \mathrm{EU} / \mathrm{ml}$ endotoxin using a commercial Limulus assay kit (Chromogenic End-point TAL with a Diazo coupling kit; Xiamen Houshiji, Fujian, China) The concentration of Ti particles used in cell experiments was $0.1 \mathrm{mg} / \mathrm{ml}$. Previous studies have demonstrated that such particles are similar to wear debris particles retrieved from periprosthetic tissues [23, 24].

\section{Cell culture and treatment}

The RAW 264.7 mouse macrophage cell line was purchased from the American Type Culture Collection (Rockville, MD, USA) and grown at $37^{\circ} \mathrm{C}$ in a humidified atmosphere with $5 \% \mathrm{CO}_{2}$ in high glucose Dulbecco's Modified Eagle's Medium (DMEM; Gibco, Grand Island, NY, USA) containing 10\% fetal bovine serum (Gibco). LPS (Sigma-Aldrich, St. Louis, MO, USA) was solubilized in PBS at $1 \mathrm{mg} / \mathrm{mL}$ and stored at $-20^{\circ} \mathrm{C}$. Prior to use, 


\section{Cellular Physiology Cell Physiol Biochem 2015;35:1857-1867 \begin{tabular}{ll|l} 
and Biochemistry & $\begin{array}{l}\text { DOI: 10.1159/000373996 } \\
\text { Published online: March 26, 2015 }\end{array}$ & $\begin{array}{l}\text { ( ) 2015 S. Karger AG, Basel } \\
\text { www.karger.com/cpb }\end{array}$ \\
\hline
\end{tabular} \\ Chen et al.: Wear Particles Promote Inflammation Through NOX}

LPS was reconstituted to $1 \mu \mathrm{g} / \mathrm{mL}$ in DMEM or PBS. The NOX inhibitor 4'-hydroxy-3'-methoxyacetophenone (apocynin; Sigma-Aldrich) was dissolved in ethanol before use.

Cells were plated in 6-well plates at a density of $\sim 10^{6}$ cells per well, incubated overnight, and then treated with Ti particles or LPS. To study the role of Ti particles in LPS-activated macrophages, cells were incubated in medium containing $1 \mu \mathrm{g} / \mathrm{mL}$ LPS for 15-60 min, with or without pre-exposure to Ti particles for $12 \mathrm{~h}$. To examine the effect of apocynin on Ti particle-treated macrophages, cells were pre-incubated with apocynin for $30 \mathrm{~min}$ prior to the addition of Ti particles.

\section{Measurement of intracellular ROS levels by flow cytometry}

The fluorescence probe 2',7'-dichlorodihydrofluorescein diacetate $\left(\mathrm{H}_{2} \mathrm{DCFDA}\right.$; Invitrogen Co., Carlsbad, CA,USA) was used to measure intracellular ROS production in RAW 264.7 macrophages. Following the various treatments, cells were collected and resuspended in PBS containing $5 \mu \mathrm{mol} / \mathrm{L} \mathrm{H}_{2}$ DCFDA and incubated for $20 \mathrm{~min}$ at $37^{\circ} \mathrm{C}$ in the dark, and then washed in PBS to remove the extracellular probe. The fluorescence intensity was then measured by flow cytometry (Beckman-Coulter, Fullerton, CA, USA) with excitation and emission wavelengths of $488 \mathrm{~nm}$ and $525 \mathrm{~nm}$, respectively. A total of 40,000 macrophages were analyzed for each sample. Data were analyzed using Kaluza software (Beckman-Coulter).

\section{Western blotting}

RAW 264.7 macrophages were lysed in lysis solution containing a protease inhibitor cocktail. After centrifugation at $12,000 \mathrm{rpm}$ and $4^{\circ} \mathrm{C}$ for $20 \mathrm{~min}$, the protein in the supernatant was separated by $12 \%$ sodium dodecyl sulfate polyacrylamide gel electrophoresis and transferred to nitrocellulose membranes, which were blocked in 5\% skim milk for $30 \mathrm{~min}$ at room temperature and probed with antibodies against NOX-1 (1:1000), NOX-2 (1:200) (Santa Cruz Biotechnology, Inc.), CAT (1:1000), NF- кB p65 (1:1000), phospho-NF- $\kappa$ B p65 (1:1000), and $\beta$-actin (1:1000) (Cell Signaling Technology, Beverly, MA, USA) overnight at $4{ }^{\circ} \mathrm{C}$. The anti-NF- $\mathrm{BB}$ p65 and anti- $\beta$-actin antibodies were used as internal controls. On the next day, membranes were incubated with appropriate horseradish peroxidase-conjugated secondary antibody (1:3000; Jackson Immunoresearch, West Grove, PA, USA) for $2 \mathrm{~h}$ at room temperature. Protein bands were detected with an enhanced chemiluminescence system and analyzed using Image J software (National Institutes of Health, Bethesda, MD, USA).

\section{Enzyme-linked immunosorbent assay (ELISA)}

The supernatant was collected from cultured cells and the TNF- $\alpha$ level was measured using an ELISA kit (R\&D Systems, Minneapolis, MN, USA) according to the manufacturer's instructions. The absorbance at $450 \mathrm{~nm}$ was measured using a microplate reader (Bio-Rad Laboratories, Hercules, CA, USA). The TNF- $\alpha$ concentration was calculated based on a standard curve.

\section{Statistical analysis}

All data are presented as the mean \pm standard error of the mean (SEM). SPSS 13.0 software (SPSS Inc., Chicago, IL, USA) was used for data analysis, which was performed using one-way analysis of variance or the Student's $t$-test. A post-hoc least significant difference test was performed for multiple comparisons among groups. A P value $<0.05$ was considered statistically significant.

\section{Results}

NOX-1 and -2 are highly expressed in membrane tissues at the interface of aseptic loosening To determine the expression of ROS-related enzymes in interface membrane tissues obtained from revision THA patients, immunofluorescence was conducted to detect NOX1, NOX-2, and catalase. NOX-1 and CAT were widely expressed in all samples (Fig. 2a, c, d, f). A few scattered NOX-2-positive cells were detected in synovial membranes in primary THA, while large numbers of NOX-2 positive cells had infiltrated synovial membrane-like interface tissues of patients with aseptic loosening and this group showed a stronger NOX-2 immunoreactivity $(\mathrm{P}<0.001)$ (Fig. 2b,e,j). These results indicate the infiltration and activation of macrophages and neutrophils in aseptic loosening, since NOX-2 is mainly expressed in 


\section{Cellular Physiology Cell Physiol Biochem 2015;35:1857-1867 \begin{tabular}{l|l|l}
$: 10.1159 / 000373996$ & 2015 S. Karger AG, Basel
\end{tabular} and Biochemistry Published online: March 26, $2015 \quad$ www.karger.com/cpb
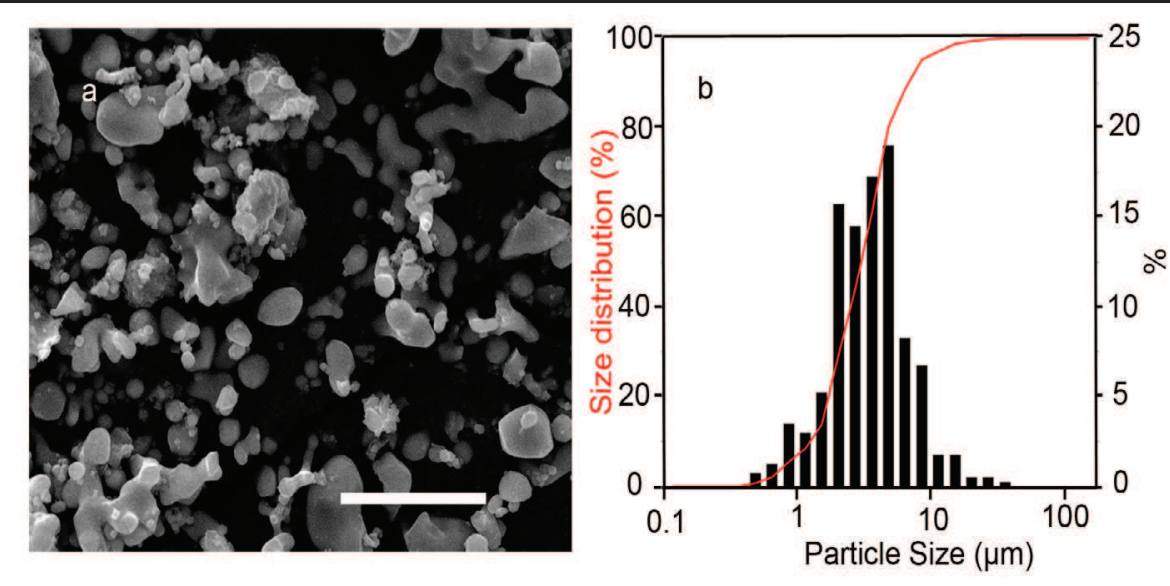

Fig. 1. (a) Scanning electron micrograph of Ti particles used in the experiments. Original magnification $6000 \times$; scale bar $=10 \mu \mathrm{m}$. (b) Histogram of the particle distribution pattern.

these cell types [16]. A significant increase in NOX-1 immunoreactivity was also observed in synovial membrane-like interface tissues of patients with aseptic loosening compared to synovial membranes of primary THA patients $(\mathrm{P}<0.001)$ (Fig. $2 \mathrm{a}, \mathrm{d}, \mathrm{i})$. In contrast, there was no significant difference in CAT expression between these groups (Fig. 2c, f, k). The specificity of the staining was evidenced by the absence of signal in tissue samples stained with non-immune rabbit or goat IgG instead of specific primary antibodies (Fig. 2g, h).

\section{Ti particles attenuate LPS-induced NF- $\kappa B$ phosphorylation in macrophages}

Our previous studies demonstrated that pre-exposure to Ti particles for $12 \mathrm{~h}$ decreased TNF- $\alpha$ and IL-1 $\beta$ release by LPS-activated RAW 264.7 macrophages [25]. In the present study, we examined whether this involves the upstream signaling protein NF- $\kappa B$. Stimulation with LPS induced the rapid phosphorylation of NF- $\mathrm{KB}$ in macrophages (particularly at $30 \mathrm{~min}$ ); by comparison, only modest NF- $\mathrm{\kappa B}$ phosphorylation was observed in macrophages incubated with Ti particles at all time points ( $\mathrm{P}<0.001)$ (Fig. 3). However, the level of phosphorylated $\mathrm{NF}-\kappa \mathrm{B}$ was reduced in LPS-stimulated macrophages (particularly at 30 and $60 \mathrm{~min}$ ) that were pre-exposed to Ti particles for $12 \mathrm{~h}$ as compared to those without pre-exposure $(\mathrm{P}<$ 0.05) (Fig. 3).

\section{Ti particles stimulate NOX-1 and -2 expression in macrophages}

Given the elevated expression of NOX-1 and -2 in the interface tissue of patients with aseptic loosening as compared to primary THA patients, we investigated whether Ti particles contribute to the induction of NOX-1 and -2 expression in RAW 264.7 macrophages in vitro. LPS - which can significantly increase NOX-1 and - 2 and decrease CAT expression in macrophages $[18,26,27]$ - served as a positive control. Incubation of macrophages with Ti particles for $12 \mathrm{~h}$ induced NOX-1 and -2 protein expression $(\mathrm{P}<0.05)$. However, unlike for LPS, Ti particles had no effect on CAT expression (Fig. 4).

Apocynin suppresses ROS generation, NF- $\kappa B$ phosphorylation, and TNF- $\alpha$ release in $T i$ particle-treated macrophages

The NOX inhibitor apocynin was used to determine whether NOX is involved in Ti particle-induced ROS generation in RAW 264.7 macrophages, as measured by flow cytometry. Pretreatment with apocynin suppressed ROS generation in LPS-stimulated cells, which is in accordance with previous studies [28]. Stimulation with Ti particles for $12 \mathrm{~h}$ significantly induced the generation of ROS in macrophages, although this effect is weaker than that with LPS $(\mathrm{P}<0.001)$. However, pretreatment with 30 or $100 \mu \mathrm{M}$ apocynin for $30 \mathrm{~min}$ prior to the addition of Ti particles suppressed ROS levels compared to macrophages treated with 


\section{Cellular Physiology Cell Physiol Biochem 2015;35:1857-1867 \begin{tabular}{|l|l|l}
\hline DOI: 10.1159/000373996 & (c) 2015 S. Karger AG, Basel
\end{tabular} and Biochemistry Published online: March 26, $2015 \quad$ www.karger.com/cpb
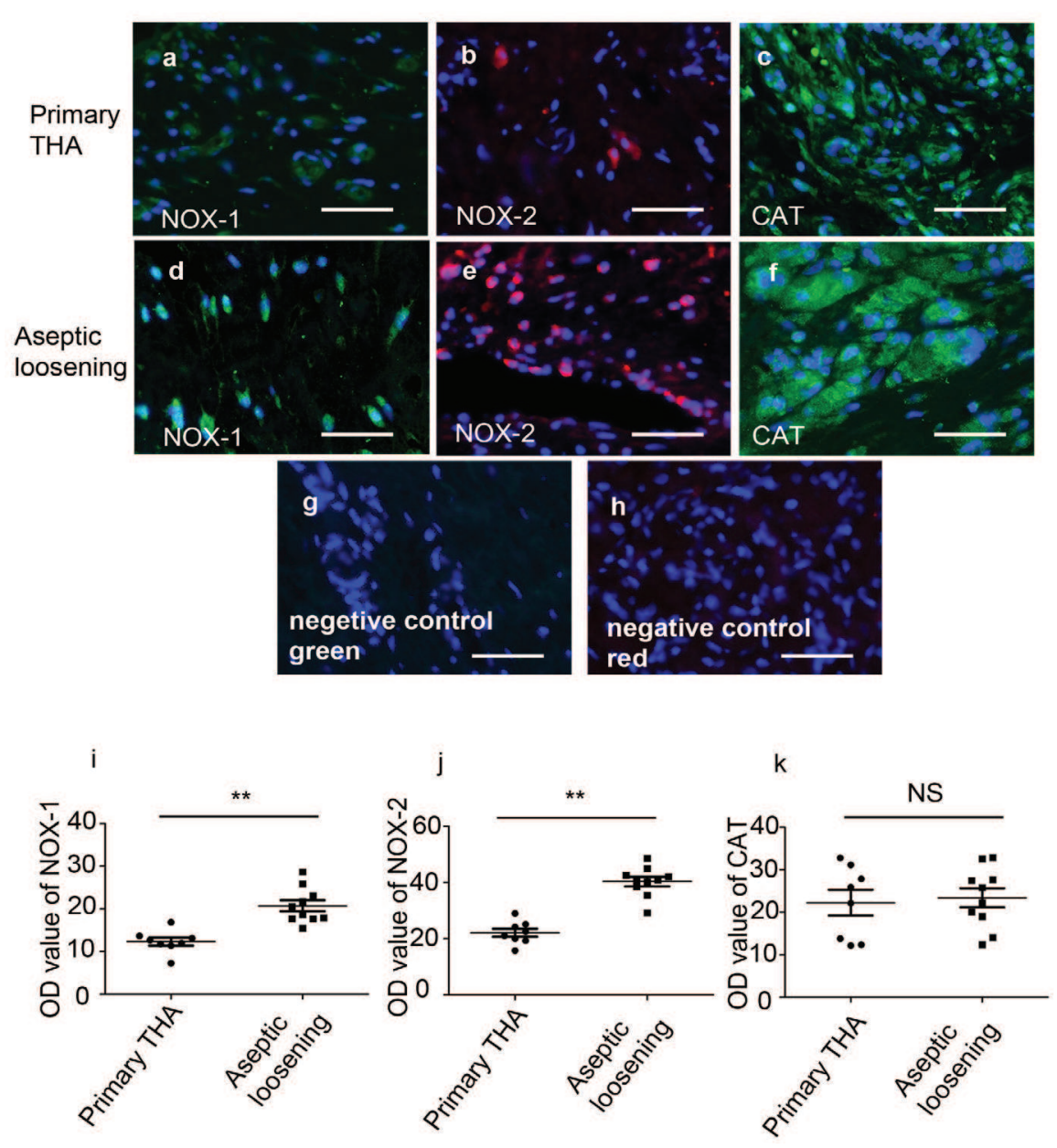

Fig. 2. NOX-1 and -2 and CAT expression in patient tissues. Expression of NOX-1 (green), NOX-2 (red), and CAT (green) in the synovial membrane of primary THA patients $(\mathrm{a}-\mathrm{c})$ and synovial membrane-like interface membranes of prosthesis loosening patients (d-f), as visualized by Immunofluorescence staining. Sections were counterstained with DAPI to visualize cell nuclei (blue). (i-k) Quantitative analysis of NOX-1 and -2 and CAT expression. Data are shown as mean \pm SEM. ${ }^{* *} \mathrm{P}<0.001$, NS = not significant. $(\mathrm{g}, \mathrm{h})$ Negative controls (NC) were stained with non-immune rabbit or goat IgG instead of the corresponding primary specific antibodies to demonstrate the specificity of staining. Original magnification $200 \times$, Scale bar $=50 \mu \mathrm{m}$.

Ti particles alone $(\mathrm{P}<0.05)$ (Fig. 5a, b). Furthermore, after treatment with Ti particles, a marked increase in NF- $\kappa$ B phosphorylation and TNF- $\alpha$ release was observed $(\mathrm{P}<0.05)$ - an effect that was suppressed by apocynin pretreatment $(\mathrm{P}<0.05)$ (Fig. 5c, d).

\section{Discussion}

Prosthesis loosening is characterized as septic (resulting from implant-related infections) or aseptic (resulting from foreign body reactions) [29, 30]. However, recent studies have suggested that some cases of aseptic loosening may also be related to bacterial invasion that is undetectable by conventional microbial culture methods [31-34].

Our findings suggest that aseptic loosening may be initiated by stimulation from wear particles, after which a hard-to-detect, low-grade infection induces chronic inflammation 


\section{Cellular Physiology Cell Physiol Biochem 2015;35:1857-1867 \begin{tabular}{l|l} 
DOI: 10.1159/000373996 & o 2015 S. Karger AG, Basel
\end{tabular} and Biochemistry Published online: March 26, 2015 www.karger.com/cpb

Fig. 3. Effect of Ti particles on LPS-induced phosphorylation of NF-kB. (a) RAW 264.7 macrophages were pre-exposed to Ti particles for $12 \mathrm{~h}$ with or without incubation with LPS total NF- $\mathrm{KB}$ p65 expression levels were measured by western blotting. (b) Quantitative analysis of (a). The ratio of $\mathrm{p}$ - to total NF- $\kappa \mathrm{B}$ p65 is presented as the fold difference over the negative control $(\mathrm{NC})$ at each time point. Data are presented as mean \pm SEM from three independent experiments. ${ }^{*} \mathrm{P}<0.05$ vs. stimulation with LPS only, ${ }^{\#} \mathrm{P}<0.05,{ }^{\# \#} \mathrm{P}<0.001$ vs. stimulation with Ti particles only. for 15, 30, or $60 \mathrm{~min}$. Phosphorylated (p-) and

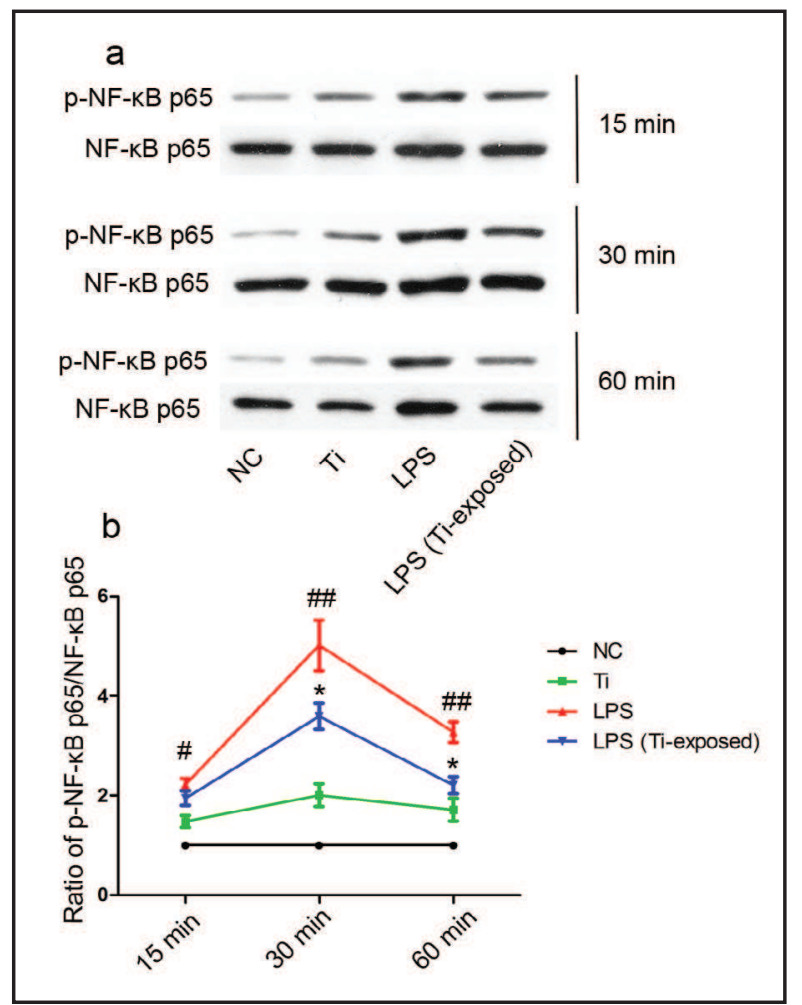

Fig. 4. Effect of Ti particles and LPS on NOX1 and -2 and CAT protein levels. RAW 264.7 macrophages were treated with Ti particles or LPS for $12 \mathrm{~h}$, and protein expression was determined by western blotting. The ratios of NOX1 and -2 and CAT to $\beta$-actin are presented as fold differences over the negative control (NC) value. Data are presented as mean \pm SEM from three independent experiments. ${ }^{*} \mathrm{P}<0.05$ vs. NC.

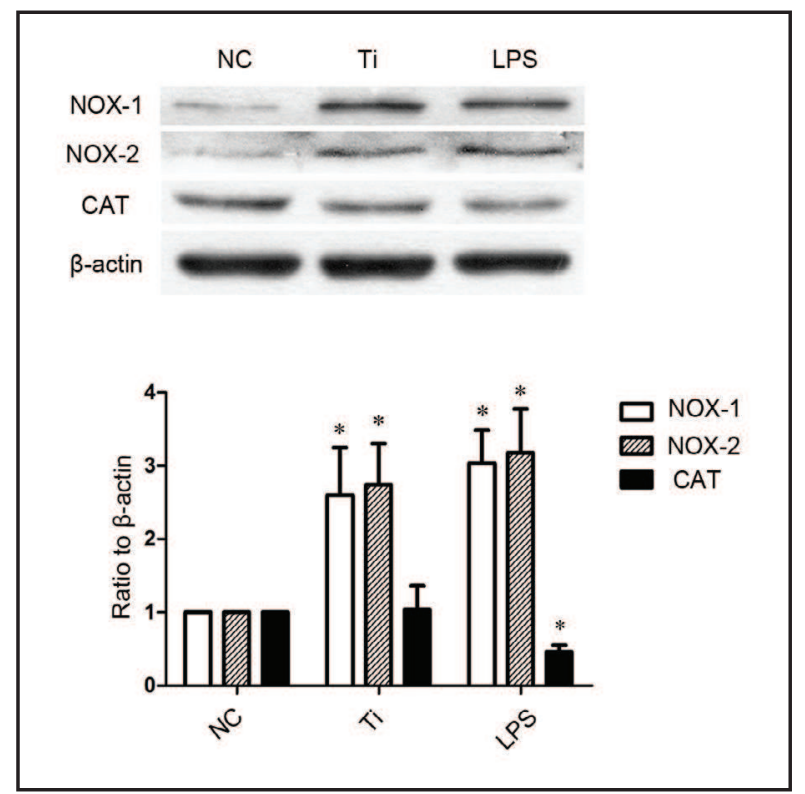

and eventual loosening of the prosthesis. Our previous study showed that the production of proinflammatory cytokines by macrophages is only weakly stimulated by wear particles, whereas it is strongly stimulated by LPS. However, macrophages first exposed to wear particles produced only a moderate amount of cytokine upon LPS stimulation [25]. A similar effect was observed in the present study - that is, the strong LPS-induced activation of NF$\kappa B$ (Fig. 3) and ROS generation [35] in macrophages were attenuated by pre-exposure to Ti particles, suggesting the occurrence of LPS tolerance in macrophages, which may mimic the pathogenesis of prosthesis loosening. In normal tissues, LPS triggers a strong, acute, transient inflammation as a protective response that allows the removal of noxious stimuli and the healing of damaged tissue [36, 37]. However, wear particles in peri-implant tissues 


\section{Cellular Physiology Cell Physiol Biochem 2015;35:1857-1867 \begin{tabular}{l|l} 
and Biochemistry & DOI: 10.1159/000373996 \\
Published online: March 26, 2015 & $\begin{array}{l}\text { O 2015 S. Karger AG, Basel } \\
\text { www.karger.com/cpb }\end{array}$ \\
\cline { 2 - 3 }
\end{tabular}

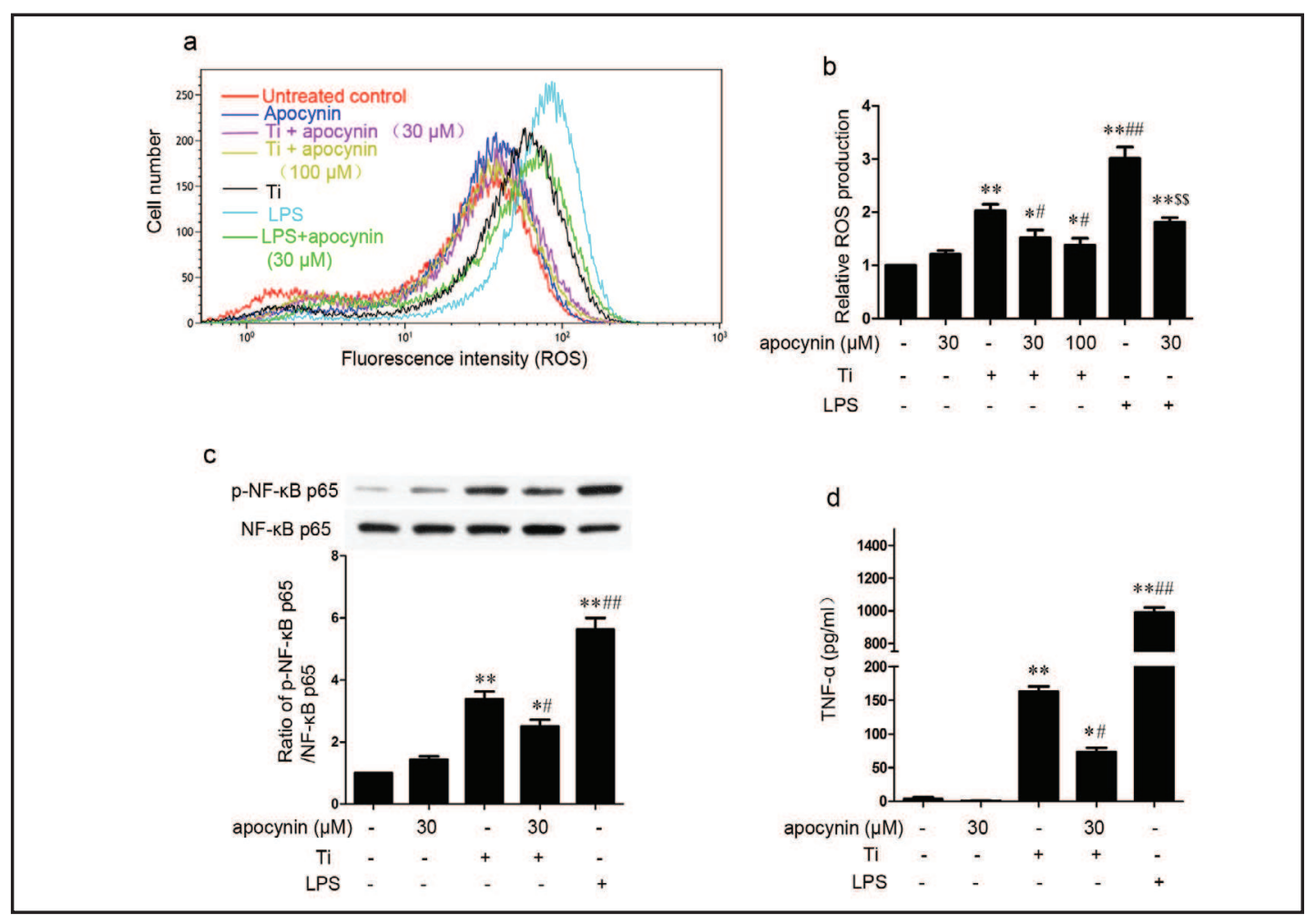

Fig. 5. Effect of apocynin on Ti particle-induced ROS generation, NF- $\kappa B$ phosphorylation, and TNF- $\alpha$ release. RAW 264.7 macrophages were pretreated with apocynin for $30 \mathrm{~min}$ and incubated with Ti particles or LPS for $30 \mathrm{~min}$ (for p-NF- $\kappa \mathrm{B}$ ) or $12 \mathrm{~h}$ (for ROS and TNF- $\alpha$ ). (a) ROS generation induced by Ti particles or LPS was suppressed by apocynin, as determined by flow cytometry. Quantitative analysis of flow cytometry results (b), western blot analysis of NF- $\kappa$ B phosphorylation (c), and TNF- $\alpha$ expression as determined by ELISA (d) show the inhibitory effect of apocynin. Data are presented as mean \pm SEM from three independent experiments. ${ }^{*} \mathrm{P}<0.05,{ }^{* *} \mathrm{P}<0.001$ vs. NC, ${ }^{\#} \mathrm{P}<0.05$, ${ }^{\# \#} \mathrm{P}<0.001$ vs. stimulation with Ti particles only, $\$ \$ \mathrm{P}<0.001$ vs. LPS.

may cause a modest activation of NF- $\mathrm{\kappa B}$ (Fig. 3), which are consequently unable to eliminate pathogens thoroughly due to LPS tolerance [25]; this is followed by a low-grade biofilmassociated infection, chronic inflammation, and delayed loosening [38]. The present findings confirm our previous hypothesis that wear particles induce an immunosuppressive state in periprosthetic tissues $[25,30]$.

The generation of large amounts of ROS (known as respiratory burst) plays a critical role in innate immunity against microbial pathogens by acting as agents that can effectively oxidize and kill invading pathogens [19]. However, if the amount of ROS is relatively low or moderate, they act as second messengers to activate NF- $\mathrm{KB}$ and the subsequent release of proinflammatory cytokines such as TNF- $\alpha$ and IL-1 $\beta[15,39]$, which may result in chronic inflammation $[40,41]$. As shown here, Ti particles induced the generation of only moderate amounts of ROS in macrophages as compared to LPS treatment (Fig. 5). Similar to the modest activation of NF- $\mathrm{KB}$ caused by Ti particles, a moderate amount of ROS is a risk factor for LPS tolerance, persistent inflammation, and delayed loosening.

NOX enzymes are the major source of ROS in immune cells [15, 42]. NOX-2 activity is one of the earliest and most robust defense mechanisms of phagocytes against pathogens [42]. To identify enzymes responsible for wear particle-induced ROS production, the expression of NOX-1 and -2 and the antioxidant CAT was evaluated in response to Ti particle stimulation. NOX-1 and -2 expression was upregulated in macrophages by Ti particles, which is similar to the effect of LPS stimulation (Fig. 4). In accordance with in vitro studies, NOX-1 and -2 were highly expressed in aseptic loosening tissues, which was indicative of oxidative stress 


\section{Cellular Physiology Cell Physiol Biochem 2015;35:1857-1867 \begin{tabular}{ll|l} 
and Biochemistry & $\begin{array}{l}\text { DOI: 10.1159/000373996 } \\
\text { Published online: March 26, 2015 }\end{array}$ & $\begin{array}{l}\text { ○ 2015 S. Karger AG, Basel } \\
\text { www.karger.com/cpb }\end{array}$ \\
\hline
\end{tabular} Chen et al.: Wear Particles Promote Inflammation Through NOX}

around the implant (Fig. 2). Pretreatment with apocynin suppressed Ti particle-induced ROS generation, confirming the role of NOX-1 and -2 in response to wear particles (Fig. 5).

Increased bone resorption due to cytokine signaling from wear particle-stimulated macrophages is a major cause of peri-implant osteolysis around joint prostheses [6]. Among proinflammatory cytokines produced by activated macrophages, TNF- $\alpha$ is a key factor involved in osteolysis, which plays an important role in osteoclast differentiation, bone resorption by mature osteoclasts, and osteoclast survival $[6,43,44]$. In this report, we show that the suppression of NOX-mediated ROS production by apocynin attenuated NF- $\kappa B$ activation and TNF- $\alpha$ release, thus suggesting a protective effect of apocynin in preventing prosthesis loosening.

However, apocynin does not completely inhibit ROS production and their downstream effects on NF- $\kappa B$ phosphorylation and TNF- $\alpha$ release upon wear particles stimulation, suggesting these particles may induce ROS generation through other pathways. Besides NOX pathway, mitochondrial pathway is an important source of ROS production in response to detrimental stimuli [45]. Our further studies will focus on mitochondria-derived ROS in prosthesis loosening.

In conclusion, the present findings demonstrate that wear particle-induced LPS tolerance in macrophages may play a role in low-grade infection and loosening. Ti particles induce a moderate amount of ROS generation through activation of the NOX signaling pathway in macrophages, resulting in a state of persistent inflammation and delayed loosening. The immunomodulatory effects of apocynin in Ti particle-activated macrophages-including inhibitory effects on ROS generation, NF- $\kappa$ B phosphorylation, and TNF- $\alpha$ secretion-imply that NOX inhibitors or other antioxidants may serve as therapeutic agents against wear particle-mediated chronic inflammation and prosthesis loosening.

\section{Acknowledgments}

This work was supported by grants from National Natural Science Foundation of China (no. 81171710), the High Technological Industrialization Projects of Guangdong Province, China (no. 2011B010500012), and the International Cooperation of Science and Technology of Guangdong Province, China (no. 2013B051000040).

\section{Disclosure Statement}

All the authors declare no competing interests.

\section{References}

1 Sheng P, Lehto M, Kataja M, Halonen P, Moilanen T, Pajamaki J: Patient outcome following revision total knee arthroplasty: a meta-analysis. Int Orthop 2004;28:78-81.

2 Dai M, Jiang C, Liu X, Li Z, Cheng X, Zou Y, Nie T: Wear particle-mediated expressions of pro-inflammatory cytokines, NF- $\kappa B$ and RANK were impacted by lanthanum chloride in RAW264.7 cells. J Rare Earth 2013;31:531-540.

3 Purdue PE, Koulouvaris P, Potter HG, Nestor BJ, Sculco TP: The cellular and molecular biology of periprosthetic osteolysis. Clin Orthop Relat Res 2007;454:251-261.

$4 \quad$ Hallab NJ, Jacobs JJ: Biologic effects of implant debris. Bull NYU Hosp Jt Dis 2009;67:182-188.

5 Yang F, Wu W, Cao L, Huang Y, Zhu Z, Tang T, Dai K: Pathways of macrophage apoptosis within the interface membrane in aseptic loosening of prostheses. Biomaterials 2011;32:9159-9167.

6 Ingham E, Fisher J: The role of macrophages in osteolysis of total joint replacement. Biomaterials 2005;26:1271-1286. 


\section{Cellular Physiology Cell Physiol Biochem 2015;35:1857-1867 \begin{tabular}{l|l|l}
\hline DOI: 10.1159/000373996 & (C) 2015 S. Karger AG, Basel
\end{tabular} and Biochemistry Published online: March 26, $2015 \quad$ www.karger.com/cpb}

Chen et al.: Wear Particles Promote Inflammation Through NOX

7 Baumann B, Seufert J, Jakob F, Noth U, Rolf O, Eulert J, Rader CP: Activation of NF-kappaB signalling and TNFalpha-expression in THP-1 macrophages by TiAlV- and polyethylene-wear particles. J Orthop Res 2005;23:1241-1248.

8 Goodman SB, Lind M, Song Y, Smith RL: In vitro, in vivo, and tissue retrieval studies on particulate debris. Clin Orthop Relat Res 1998:25-34.

9 Bauer TW: Particles and periimplant bone resorption. Clin Orthop Relat Res 2002:138-143.

10 McEvoy A, Jeyam M, Ferrier G, Evans CE, Andrew JG: Synergistic effect of particles and cyclic pressure on cytokine production in human monocyte/macrophages: proposed role in periprosthetic osteolysis. Bone 2002;30:171-177.

11 Samelko L, Caicedo MS, Lim SJ, Della-Valle C, Jacobs J, Hallab NJ: Cobalt-alloy implant debris induce HIF1alpha hypoxia associated responses: a mechanism for metal-specific orthopedic implant failure. PLoS One 2013;8:e67127.

12 Raghunathan VK, Devey M, Hawkins S, Hails L, Davis SA, Mann S, Chang IT, Ingham E, Malhas A, Vaux DJ, Lane JD, Case CP: Influence of particle size and reactive oxygen species on cobalt chrome nanoparticlemediated genotoxicity. Biomaterials 2013;34:3559-3570.

13 Yamada M, Ueno T, Minamikawa H, Sato N, Iwasa F, Hori N, Ogawa T: N-acetyl cysteine alleviates cytotoxicity of bone substitute. J Dent Res 2010;89:411-416.

14 Gloire G, Legrand-Poels S, Piette J: NF-kappaB activation by reactive oxygen species: fifteen years later. Biochem Pharmacol 2006;72:1493-1505.

15 Lambeth JD, Neish AS: Nox enzymes and new thinking on reactive oxygen: a double-edged sword revisited. Annu Rev Pathol 2014;9:119-145.

16 Lambeth JD: NOX enzymes and the biology of reactive oxygen. Nat Rev Immunol 2004;4:181-189.

17 Mates JM: Effects of antioxidant enzymes in the molecular control of reactive oxygen species toxicology. Toxicology 2000;153:83-104.

18 Maitra U, Singh N, Gan L, Ringwood L, Li L: IRAK-1 contributes to lipopolysaccharide-induced reactive oxygen species generation in macrophages by inducing NOX-1 transcription and Rac1 activation and suppressing the expression of antioxidative enzymes. J Biol Chem 2009;284:35403-35411.

19 Babior BM: The respiratory burst of phagocytes. J Clin Invest 1984;73:599-601.

20 Stolk J, Hiltermann TJ, Dijkman JH, Verhoeven AJ: Characteristics of the inhibition of NADPH oxidase activation in neutrophils by apocynin, a methoxy-substituted catechol. Am J Respir Cell Mol Biol 1994;11:95-102.

21 Hou C, Zhang Y, Yu S, Li Z, Zhai Q, Li Z, Zhang X, Xiao J, Sheng P: Presence of interleukin-17C in the tissue around aseptic loosened implants. Int Orthop 2013;37:953-959.

22 Rakshit DS, Ly K, Sengupta TK, Nestor BJ, Sculco TP, Ivashkiv LB, Purdue PE: Wear debris inhibition of antiosteoclastogenic signaling by interleukin- 6 and interferon-gamma. Mechanistic insights and implications for periprosthetic osteolysis. J Bone Joint Surg Am 2006;88:788-799.

23 Liu F, Zhu Z, Mao Y, Liu M, Tang T, Qiu S: Inhibition of titanium particle-induced osteoclastogenesis through inactivation of NFATc1 by VIVIT peptide. Biomaterials 2009;30:1756-1762.

24 Geng DC, Xu YZ, Yang HL, Zhu XS, Zhu GM, Wang XB: Inhibition of titanium particle-induced inflammatory osteolysis through inactivation of cannabinoid receptor 2 by AM630. J Biomed Mater Res A 2010;95:321326.

25 Zhang Y, Yu S, Xiao J, Hou C, Li Z, Zhang Z, Zhai Q, Lehto M, Konttinen YT, Sheng P: Wear particles promote endotoxin tolerance in macrophages by inducing interleukin-1 receptor-associated kinase-M expression. J Biomed Mater Res A 2013;101:733-739.

26 Huo Y, Rangarajan P, Ling EA, Dheen ST: Dexamethasone inhibits the Nox-dependent ROS production via suppression of MKP-1-dependent MAPK pathways in activated microglia. BMC Neurosci 2011;12:49.

27 Meng T, Yu J, Lei Z, Wu J, Wang S, Bo Q, Zhang X, Ma Z, Yu J: Propofol reduces lipopolysaccharide-induced, NADPH oxidase (NOX 2) mediated TNF- alpha and IL-6 production in macrophages. Clin Dev Immunol 2013;2013:325481.

28 Lee IT, Shih RH, Lin CC, Chen JT, Yang CM: Role of TLR4/NADPH oxidase/ROS-activated p38 MAPK in VCAM-1 expression induced by lipopolysaccharide in human renal mesangial cells. Cell Commun Signal 2012;10:33. 


\section{Cellular Physiology Cell Physiol Biochem 2015;35:1857-1867 and Biochemistry \begin{tabular}{l|l}
${ }$ Published online: March 26, $2015 }$ & $\begin{array}{l}\text { C } 2015 \text { S. Karger AG, Basel } \\
\text { www.karger.com/cpb }\end{array}$ \\
\hline
\end{tabular}}

Chen et al.: Wear Particles Promote Inflammation Through NOX

29 Takagi M, Santavirta S, Ida H, Ishii M, Takei I, Niissalo S, Ogino T, Konttinen YT: High-turnover periprosthetic bone remodeling and immature bone formation around loose cemented total hip joints. J Bone Miner Res 2001;16:79-88.

30 Zhang Y, Hou C, Yu S, Xiao J, Zhang Z, Zhai Q, Chen J, Li Z, Zhang X, Lehto M, Konttinen YT, Sheng P: IRAK-M in macrophages around septically and aseptically loosened hip implants. J Biomed Mater Res A 2012;100:261-268.

31 Tunney MM, Patrick S, Gorman SP, Nixon JR, Anderson N, Davis RI, Hanna D, Ramage G: Improved detection of infection in hip replacements. A currently underestimated problem. J Bone Joint Surg Br 1998;80:568572.

32 Clarke MT, Roberts CP, Lee PTH, Gray J, Keene GS, Rushton N: Polymerase Chain Reaction Can Detect Bacterial DNA in Aseptically Loose Total Hip Arthroplasties. Clin Orthop Relat Res 2004;427:132-137.

33 Nalepka JL, Lee MJ, Kraay MJ, Marcus RE, Goldberg VM, Chen X, Greenfield EM: Lipopolysaccharide found in aseptic loosening of patients with inflammatory arthritis. Clin Orthop Relat Res 2006:229-235.

34 Nelson CL, McLaren AC, McLaren SG, Johnson JW, Smeltzer MS: Is aseptic loosening truly aseptic? Clin Orthop Relat Res 2005:25-30.

35 Chen W, Li Z, Guo Y, Zhou Y, Zhang Y, Luo G, Yang X, Li C, Liao W, Sheng P: Wear Particles Impair Antimicrobial Activity Via Suppression of Reactive Oxygen Species Generation and ERK1/2 Phosphorylation in Activated Macrophages. Inflammation DOI: 10.1007/s10753-014-0099-4

36 Hedl M, Abraham C: Negative regulation of human mononuclear phagocyte function. Mucosal Immunol 2013;6:205-223.

37 Raetz CR, Whitfield C: Lipopolysaccharide endotoxins. Annu Rev Biochem 2002;71:635-700.

38 Costerton JW: Bacterial Biofilms: A Common Cause of Persistent Infections. Science 1999;284:1318-1322.

39 Asehnoune K, Strassheim D, Mitra S, Kim JY, Abraham E: Involvement of reactive oxygen species in Toll-like receptor 4-dependent activation of NF-kappa B. J Immunol 2004;172:2522-2529.

40 Bengtsson AA, Pettersson A, Wichert S, Gullstrand B, Hansson M, Hellmark T, Johansson AC: Low production of reactive oxygen species in granulocytes is associated with organ damage in systemic lupus erythematosus. Arthritis Res Ther 2014;16:R120.

41 Thomas CE, Darley-Usmar V: Forum on therapeutic applications of reactive oxygen and nitrogen species in human disease. Free Radic Biol Med 2000;28:1449-1450.

42 Lam GY, Huang J, Brumell JH: The many roles of NOX2 NADPH oxidase-derived ROS in immunity. Semin Immunopathol 2010;32:415-430.

43 Xu JW, Konttinen YT, Lassus J, Natah S, Ceponis A, Solovieva S, Aspenberg P, Santavirta S: Tumor necrosis factor-alpha (TNF-alpha) in loosening of total hip replacement (THR). Clin Exp Rheumatol 1996;14:643648.

44 Fuller K, Murphy C, Kirstein B, Fox SW, Chambers TJ: TNFalpha potently activates osteoclasts, through a direct action independent of and strongly synergistic with RANKL. Endocrinology 2002;143:1108-1118.

45 West AP, Brodsky IE, Rahner C, Woo DK, Erdjument-Bromage H, Tempst P, Walsh MC, Choi Y, Shadel GS, Ghosh S: TLR signalling augments macrophage bactericidal activity through mitochondrial ROS. Nature 2011;472:476-480. 